\title{
COLONIZAÇÃO POR FUNGOS MICORRÍZICOS ARBUSCULARES E TEORES DE NUTRIENTES EM CINCO CULTIVARES DE BANANEIRAS EM UM LATOSSOLO DA AMAZÔNIA ${ }^{(1)}$
}

\author{
Arlem Nascimento de Oliveira(2) \& Luiz Antonio de Oliveira ${ }^{(3)}$
}

\begin{abstract}
RESUMO
A bananeira é uma espécie de grande importância sócio-econômica na Amazônia, mas precisa de altos insumos agrícolas para ser produtiva. A associação com fungos micorrízicos arbusculares (F MAs) pode minimizar as suas necessidades nutricionais nos solos pobres da Amazônia. O presente trabalho objetivou verificar a ocorrência de associação micorrízica e os teores de nutrientes em bananeiras cultivadas em um Latossolo ácido da Amazônia. 0 bananal encontra-se deficiente em macro ( $\mathrm{Ca}, \mathrm{Mg}$ e $\mathrm{P})$ e micronutrientes ( $\mathrm{Fe}$, Mn, Zn e Cu). A colonização micorrízica foi de 54,9 \%, no cultivar Mysore; 51,5 \%, na Maçã, 47,6\%, na Pacovan; 47,3\%, na Nanica, e 44,7\%, na banana Prata, ocorrendo diferenças significativas. Os cultivares Mysore e Maçã apresentaram maiores índices de colonização radicular nos meses de janeiro e agosto, enquanto a Nanica, nos meses de julho, janeiro e agosto. Os cultivares Pacovan e Prata não apresentaram variações significativas de colonização por F MAs nas épocas estudadas. Nos cultivares, a associação micorrízica correlacionou-se significativamente com os teores de K, Mg, P e Zn no cultivar Maçã, K e P no Nanica e Zn no Prata.
\end{abstract}

Termos de indexação: fungos micorrízicos, Musa spp, nutrição mineral.

(1) Recebido para publicação em fevereiro de 2001 e aprovado em fevereiro de 2005.

(2) Doutorando em Biotecnol ogia, Universidade Federal do Amazonas, I nstituto Nacional de Pesquisas da Amazônia - UFAM/I NPA. Caixa Postal 478, CEP 69011-970 Manaus (AM). E-mail: arlem@inpa.gov.br

(3) Pesquisador do Instituto Nacional de Pesquisas da Amazônia - INPA. E-mail: luizoli@inpa.gov.br 


\author{
SUMMARY: ARBUSCULAR MYCORRHIZAE FUNGI AND NUTRIENT \\ CONTENTS IN FIVE BANANA CULTIVARS ON AN \\ AMAZONIAN OXISOL
}

\begin{abstract}
The Amazon banana plant is of great socio-economical importance, despite its requirement for high agricultural input in order to obtain good yields. An association with arbuscular mycorrhizaefungi could minimize the crop's nutritional needs in the poor soils of the Amazon. The present study aimed at verifying how the plant-fungus mycorrhizal symbiosis influences nutrient concentration in fivevarieties of adult banana plants cultivated in an acid Amazon Oxisol under fied conditions. The banana plantation was defficient in macro ( $\mathrm{Ca}, \mathrm{Mg}$ and $\mathrm{P}$ ) and micronutrients ( $\mathrm{Fe}, \mathrm{Mn}, \mathrm{Zn}$ and $\mathrm{Cu}$ ). Themycorrhizaecol onization varied from 33.6 to $66.5 \%$ of the sampled roots. The average mycorrhizae colonization was 54.9 \% in the Mysore, 51.5 \% in Maçã, 47.6 \% in Pacovan, 47.3 \% in Nanica, and $44.7 \%$ in Prata varietes, and they were significantly different from each other. The mycorrhizae colonization indexes of Mysore and Maçã varieties were highest in J anuary and August and those of Nanica peaked in J uly, J anuary and August. Pacovan and Prata did not present significant variations of mycorrhizaecol onization during thestudied period. The mycorrhizae association was significantly correlated with the leaf concentration of $\mathrm{K}$, $\mathrm{Mg}, \mathrm{P}$, and $\mathrm{Zn}$ in the Maçã variety, of $\mathrm{K}$ and $\mathrm{P}$ in Nanica, and of $\mathrm{Zn}$ in Prata variety.
\end{abstract}

Index terms: mycorrhizal fungi, Musa spp, mineral nutrition.

\section{NTRODUÇÃO}

Uma das principais limitações para a agricultura na Amazônia équea maioria dos sol os de terra firme apresenta acidez el evada e deficiências generalizadas de nutrientes, o que impede o satisfatório crescimento e desenvol vimento das plantas (Oliveira et al., 1997).

A bananeira éuma espécie semiperene de grande importância sócio-econômica na região, oferecendo ao produtor uma fonte rica de vitaminas e sais minerais, bem como uma rentabilidade contínua de receita ao longo do ano. No entanto, apesar de extensivamente cultivada, necessita de altas quantidades de insumos agrícolas para apresentar uma produção satisfatória (Medina, 1995). A adubação mineral dessa cultura passa a ser de fundamental importância, principalmentequantoao $\mathrm{K}, \mathrm{Ca}, \mathrm{Mg}$ e $\mathrm{P}$, elementos requeridos em grandes quantidades (Alves, 1991).

Uma alternativa para diminuir o uso desses insumos é proporcionar às plantas melhores condições de absorção dos nutrientes do solo. Os fungos micorrízicos arbusculares (FMAs) têm sido bastante estudados, mostrando-se importantes para a absorção de nutrientes pelas plantas (Silveira, 1992; Marschner \& Dell, 1994; Siqueira \& SagginJ únior, 1995). Oliveira et al. (1999a,b) e Oliveira \& Oliveira (2000) verificaram correlações significativas e positivas entre as colonizações micorrízicas e os teores de $\mathrm{Ca}, \mathrm{Mg}, \mathrm{P}$ e $\mathrm{K}$ no tecido foliar de espécies florestais e frutíferas da Amazônia.
Grande número de espécies da Amazônia apresenta colonização natural por F MAs (St. J ohn \& Uhl, 1983; Oliveira et al., 1999). Contudo, poucos trabal hos relatam sobrea associação micorrízica em bananeiras (Declerck et al., 1995; J aizme-Vega \& Azcón, 1995; Melo et al., 1997).

O presente estudo visou avaliar a ocorrência de FMAs no sistema radicular de cinco cultivares de bananeira, bem como verificar a existência de correlações entre a col onização micorrízica e os teores demacroemicronutrientes notecidofoliar das plantas cultivadas em um Latossolo pobre eácido da Amazônia.

\section{MATERIAL E MÉTODOS}

O estudo foi realizado em condições de campo em área experimental da $\mathrm{F}$ aculdade de Ciências Agrárias da Universidade F ederal do Amazonas, em um L atossol o Amarel o de textura argi losa (Ranzani, 1980), previamente adubado com fósforo e cultivado com bananeiras em fase de produção. As bananeiras encontravam-se em pleno sol, espaçadas entre si de $4 \times 4 \mathrm{~m}$.

Adotou-se o delineamento experimental inteiramente casual izado em esquema fatorial $5 \times 4$, em que os fatores representaram cinco cultivares de bananeiras (Maçã, Mysore, Nanica, Pacovan e Prata) e quatro épocas de coleta (dezembro/98, janeiro, jul ho e agosto/99). Os meses de dezembroe janeiro se inserem no período de chuvas regionais (inverno amazônico), enquanto julho e agosto no 
período de seca (verão amazônico) (Ribeiro, 1976). Selecionaram-se aleatoriamente cinco plantas de cada cultivar como repetição, das quais foi col etada, em cada época, uma quantidade adequada de raízes e fol has para as avaliações das colonizações micorrízicas e determinações dos teores de macro e micronutrientes nas fol has dos cultivares. Coletaramse, também, amostras desol os para avaliar seus níveis defertilidade em cada época de amostragem. Desse modo, foram feitas quatro col etas durante o período de estudo, cada uma compreendendo um total de 25 plantas.

As amostras de fol has foram col etadas da terceira fol ha emitida, sendo a cartucho considerada folha zero. Retiraram-se duas faixas do limbo, de $10 \mathrm{~cm}$ delargura, de ambos os lados, conforme preconizado por Medina (1995). As fol has foram analisadas quanto aos teores de potássio, cálcio, magnésio, fósforo, ferro, manganês, zinco e cobre, usando-se o método descrito em E mbrapa (1988).

As amostras de solo foram obtidas da rizosfera de cada cultivar, na profundidade de $0-10 \mathrm{~cm}$, e submeti das às análises químicas (Embrapa, 1997), no Laboratório de Solos da Coordenação de Pesquisas em Ciências Agronômicas/I NPA. As análises consistiram das seguintes determinações: $\mathrm{pH}\left(\mathrm{H}_{2} \mathrm{O}\right)$, $\mathrm{Ca}$, MgeAl ( $\mathrm{KCl} 1 \mathrm{~mol} \mathrm{~L}^{-1}$ ), P (extraçãopeloMehlich-1 e leitura por colorimetria), K, Mn, Zn e Fe (Mehlich-1, absorção atômica). Os resultados das análises foram: $\mathrm{pH}\left(\mathrm{H}_{2} \mathrm{O}\right)=4,6 ; \mathrm{Al}=0,5 \mathrm{cmol}_{\mathrm{c}} \mathrm{kg}^{-1} ; \mathrm{K}=0,36 \mathrm{cmol}_{\mathrm{c}} \mathrm{kg}^{-1}$; $\mathrm{Ca}=1,3 \mathrm{cmol}_{\mathrm{C}} \mathrm{kg}^{-1} ; \mathrm{Mg}=0,3 \mathrm{cmol}_{\mathrm{C}} \mathrm{kg}^{-1} ; \mathrm{P}=$ $244 \mathrm{mg} \mathrm{kg}^{-1} ; \mathrm{Zn}=3,8 \mathrm{mg} \mathrm{kg}^{-1} ; \mathrm{Mn}=4,5 \mathrm{mg} \mathrm{kg}^{-1} ; \mathrm{Fe}$ $=146 \mathrm{mg} \mathrm{kg}^{-1} ; \mathrm{Cu}=1,2 \mathrm{mg} \mathrm{kg}^{-1}$.

Para avaliar a colonização micorrízica, as raízes foram clarificadas com $\mathrm{KOH}$ a $10 \%$ e coradas em lactoglicerol com azul tripano (Kormanick et al., 1980). Adotou-se o método da lâmina para quantificar a percentagem de col onização radicular (Giovanetti \& Mosse, 1980), utilizando-se de 50 segmentos de raízes de $1 \mathrm{~cm}$ de comprimento por planta em cada época de coleta.
Os dados obtidos foram submetidos à análise de variância, empregando-se o teste de Tukey a $5 \%$ (Gomez \& Gomez, 1984). Foi realizada correlação simples, usando o nível de colonização das raízes por fungos micorrízicos como variável independente, e os teores de nutrientes nas fol has como variáveis dependentes.

\section{RESULTADOS E DISCUSSÃO}

\section{Colonização radicular por fungos micorrízicos}

A colonização radicular variou de 33,6 a 66,5 \%, ocorrendo diferenças significativas entre os cultivares e as épocas de coleta (Quadro 1). O cultivar Mysore foi o mais colonizado, diferindo estatisticamente dos demais, exceto do cultivar Maçã. A média geral da colonização mi corrízica foi de 49,2 \%, apesar de a área estudada ter apresentado el evado teor de fósforo, o que normal mente diminui a colonização micorrízica (Abbott \& Robson, 1991; Brundrett, 1991; Saggin-J únior et al., 1994). Dessa forma, a percentagem de colonização radicular aparentemente não foi inibida pelo fósforo disponível, visto que apresentou níveis semel hantes aos obtidos por outros autores (Iyer et al., 1988; Melo et al., 1997).

Siqueira (1994) afirma que os níveis de fósforo no solo interferem na colonização radicular por FMAs eque os efeitos destenutriente na col onização diferem entre as espécies. Por essa razão, segundo o autor, a quantidade de $\mathrm{P}$ requerida para inibir a colonização depende da capacidade de absorção e translocação pela espécie vegetal.

Quanto às médias das épocas, a colonização radicular pelos fungos micorrízicos no mês de dezembro foi significativamente inferior à dos demais meses de coleta, apresentando uma colonização média de 38,5 \%. Observou-se, ainda,

Quadro 1. Colonização radicular por fungos micorrízicos em diferentes cultivares de bananeiras em um Latossolo Amarelo da região de Manaus (AM)

\begin{tabular}{|c|c|c|c|c|c|}
\hline \multirow{2}{*}{ Cultivar } & \multicolumn{4}{|c|}{ É poca de coleta } & \multirow{2}{*}{ Média } \\
\hline & Dezembro/98 & J aneiro/99 & J ulho/99 & Agosto/99 & \\
\hline & & & $\%$ & 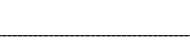 & + \\
\hline Maçã & $33,6 A c^{(1)}$ & $66,5 \mathrm{~A} a$ & $52,0 \mathrm{~A} \mathrm{~b}$ & $54,0 \mathrm{AB} a b$ & $51,5 \mathrm{AB}$ \\
\hline Mysore & $38,4 \mathrm{~A} \mathrm{C}$ & $66,4 \mathrm{~A} a$ & $52,2 \mathrm{~A} \mathrm{~b}$ & $62,5 \mathrm{~A} \mathrm{ab}$ & $54,9 \mathrm{~A}$ \\
\hline Nanica & $36,2 \mathrm{~A} \mathrm{~b}$ & $48,4 \mathrm{~B}$ ab & $57,3 \mathrm{~A}$ a & $47,1 \mathrm{~B} a b$ & $47,3 \mathrm{~B}$ \\
\hline Pacovan & $36,2 \mathrm{~A} a$ & $44,6 \mathrm{~B} \mathrm{a}$ & $54,9 \mathrm{~A}$ a & $47,5 \mathrm{~B} \mathrm{a}$ & $47,6 \mathrm{~B}$ \\
\hline Prata & $43,4 \mathrm{~A}$ a & $40,6 \mathrm{~B}$ a & $51,3 \mathrm{~A} a$ & $46,0 \mathrm{~B}$ a & $44,7 \mathrm{~B}$ \\
\hline Média/época & $38,5 \mathrm{~b}$ & 53,3 a & 53,6 a & $51,4 a$ & 49,2 \\
\hline
\end{tabular}

\footnotetext{
(1) As médias seguidas de mesma letra maiúscula, na vertical, ou minúscula, na horizontal, não diferem pelo teste de Tukey a 1 \%.
} 
interação significativa entre os cultivares eas épocas decol eta. Os cultivares Mysoree Maçã apresentaram maiores percentuais de colonização nos meses de janeiro e agosto, enquanto o cultivar Nanica nos meses de julho, janeiro e agosto. Os cultivares Pacovan e o Prata não apresentaram variações significativas entre as épocas de avaliação. Dentro deuma mesma época, houve diferenças significativas entre os cultivares nos meses de janeiro e agosto; porém, em dezembro e julho, não diferiram entre si quanto à colonização micorrízica (Quadro 1). Variações quanto à emissão de novas raízes nos meses de amostragem poderiam explicar essas pequenas diferenças entre os cultivares, uma vez que os fungos micorrízicos col onizam as raízes mais finas enovas dosistema radicular da planta (Silveira, 1992).

Comparativamente, ovalor médio de col onização observado para o cultivar Mysore foi semel hanteao obtido por Melo et al. (1997), que registraram percentuais de col onização de $55 \%$ para esse cultivar em bananais na região do Vale São Francisco. Oliveira et al. (1999a) observaram, nos cultivares Mysore e Prata, colonizações médias de 66,7 e $54,3 \%$, respectivamente, em plantios experimentais em um Latossol o Amarelo da Amazônia.

\section{Teores de nutrientes na parte aérea}

Apesar de ter sido feita uma análise foliar em cada uma das quatro épocas, não se observou diferença estatística entre os meses amostrados. Em vista disso, os dados foram simplificados no quadro 2 , onde aparecem apenas as médias dos cultivares. Analisando os teores médios dos nutrientes nas fol has (médias das quatro épocas de coletas), observou-se que não houve diferenças significativas entreos cultivares de bananeiras quanto ao $\mathrm{Mn}$, mas houve nos teores dos demais nutrientes dependendo do cultivar avaliado. Os cultivares Maçã, Nanica e Prata destacaram-se quanto aos teores de K, Ca, Fe e $\mathrm{Cu}$ nas folhas, enquanto Nanica e Prata apresentaram maior teor de Mg e Zn. O cultivar
Mysore apresentou os maiores teores de $\mathrm{Fe} \mathrm{e} \mathrm{Cu}$, enquanto Pacovan apresentou mai ores teores de $\mathrm{Mg}$ e $P$, sem diferir estatisticamente da banana Prata (Quadro 2).

Dentre os cinco cultivares, o Mysore e o Pacovan apresentaram as menores médias de teores de $\mathrm{Ca}$, enquanto no Maçã os valores foram mais el evados, não diferindo significativamente dos cultivares Nanica e Prata. Com relação ao Mg, os cultivares Nanica, Pacovan e Prata apresentaram os maiores teores, ao passo que o Mysore o menor, resultando em diferenças significativas entre os cultivares avaliados. Os teores de $P$ variaram em média de 0,9 a $1,6 \mathrm{~g} \mathrm{~kg}^{-1}$ entre os cultivares, com a Maçã, Pacovan ea Prata destacando-se com mai ores teores. Quanto ao K, os resultados mostraram teores variando de 15,7 a 33,4 $\mathrm{g} \mathrm{kg}^{-1}$ entre as bananeiras. Nos cultivares MysoreePacovan, foram aqueles com os menores teores, enquanto no Maçã, Nanica e Prata, os teores foram mais el evados (Quadro 2).

Alguns estudos sobre nutrição potássica (Rodriguez-Goméz, 1980; Malavolta, 1981; Silva, 1997) indicaram satisfatórios teores de K variando de 25 a $30 \mathrm{~g} \mathrm{~kg}^{-1}$ no limbo foliar de bananeiras. Portanto, nas condições experimentais, esse nutriente apresentou-se em níveis adequados para os cultivares Maçã, Nanica e Prata, estando, contudo, em baixas concentrações para os outros dois cultivares (Quadro 2).

Os níveis nutricionais adequados para a cultura da banana quanto ao $\mathrm{Ca}, \mathrm{Mg}$ e $\mathrm{P}$ correspondem a $15,4 \mathrm{e}^{\mathrm{g} \mathrm{kg}^{-1}}$, respectivamente (Silva, 1997). Com base nesses valores, observa-se (Quadro 2 ) que os teores desses elementos encontram-se em concentrações inferiores aos níveis mencionados pelo autor.

O comportamento relativo dos cultivares, no que tange aos teores de macronutrientes nas fol has, apresentou, em síntese, a seguinte ordem: K: Prata $=$ Maçã $=$ Nanica; Prata $>$ Mysore $=$ Pacovan; Ca: Maçã

Quadro 2. Teores de nutrientes na biomassa foliar de cultivares de bananei ras em um Latossolo Amarelo da região de Manaus (AM). Médias de quatro épocas de coleta, cinco repetições

\begin{tabular}{|c|c|c|c|c|c|c|c|c|}
\hline Cultivar & $\mathbf{K}$ & $\mathrm{Ca}$ & Mg & $\mathbf{P}$ & $\mathbf{F e}$ & Mn & Zn & $\mathrm{Cu}$ \\
\hline & \multicolumn{4}{|c|}{$\mathrm{g} \mathrm{kg}^{-1}$} & \multicolumn{4}{|c|}{$\mathrm{mg} \mathrm{kg}^{-1}$} \\
\hline Maçã & 29,6 a (1) & $7,7 \mathrm{a}$ & $2,5 \mathrm{~b}$ & $1,5 \mathrm{a}$ & 86,7 a & 18,6 a & $18,4 \mathrm{~b}$ & $7,5 \mathrm{a}$ \\
\hline Mysore & 15,7 b & $3,0 \mathrm{~b}$ & $1,7 \mathrm{C}$ & $0,9 \mathrm{~b}$ & 89,2 a & 23,2 a & $17,2 \mathrm{~b}$ & $6,8 a b$ \\
\hline Nanica & $28,2 \mathrm{a}$ & $6,2 a b$ & $3,3 \mathrm{a}$ & $1,1 \mathrm{~b}$ & 95,2 a & 67,2 a & 21,0 a & $9,0 \mathrm{a}$ \\
\hline Pacovan & $19,0 \mathrm{~b}$ & $3,0 \mathrm{~b}$ & $2,8 a b$ & $1,6 \mathrm{a}$ & $47,0 \mathrm{~b}$ & 14,8 a & $18,0 \mathrm{~b}$ & $4,1 \mathrm{~b}$ \\
\hline Prata & $33,4 a$ & $4,5 a b$ & $3,3 a$ & $1,6 \mathrm{a}$ & 89,3 a & 42,2 a & $19,1 \mathrm{ab}$ & $8,7 \mathrm{a}$ \\
\hline Médias & 25,2 & 4,9 & 2,7 & 1,3 & 81,5 & 33,2 & 18,7 & 7,2 \\
\hline
\end{tabular}

${ }^{(1)}$ As médias com letras iguais, nas colunas, não diferem pelo teste de Tukey a $5 \%$. 
$=$ Nanica $=$ Prata; Maçã $>$ Mysore $=$ Pacovan; Mg: Nanica $=$ Prata $=$ Pacovan; Nanica $>$ Maçã $>$ Mysore; P: Prata $=$ Pacovan $=$ Maçã; Prata $>$ Nanica $=$ Mysore .

Os teores foliares de macronutrientes em todos os cultivares estudados apresentaram a seguinte ordem decrescente $\mathrm{K}>\mathrm{Ca}>\mathrm{Mg}>\mathrm{P}$. Os teores de $\mathrm{K}$ foram sempre superiores aos de $\mathrm{Ca}, \mathrm{Mg}$ e $\mathrm{P}$ (Quadro 2), confirmando os estudos realizados por Rodriguez-Goméz (1980), Borges \& Cintra (1985) e Silva (1997), pelos quais as bananeiras acumulam maiores quantidades do elemento em relação aos demais macronutrientes. O K é o nutriente que a bananeira necessita em maior quantidade, atuando diretamente no metabol ismo e desenvol vimento da planta (Medina, 1995).

Quanto aos micronutrientes, o cultivar Nanica mostrou-se com um maior teor de Zn nas folhas, quando comparado com os cultivares Maçã, Mysoure e Pacovan. O Fe e o Cu foram observados em menores teores no tecido foliar da banana Pacovan, diferindo estatisticamente das demais bananeiras avaliadas. Com relação ao Mn, não houve diferenças significativas entre os cultivares.

Os níveis nutricionais satisfatórios à cultura da banana quanto ao $\mathrm{Fe}, \mathrm{Mn}$, Zn e Cu correspondem a $110,236,34$ e $28 \mathrm{mg} \mathrm{kg}^{-1}$, respectivamente

Quadro 3. Equações de regressão relacionando a colonização micorrízica (\%) e os teores de macro (g kg-1) e micronutrientes $\left(\mathrm{mg} \mathrm{kg}^{-1}\right)$ no tecido foliar dos cultivares estudados

\begin{tabular}{|c|c|c|c|}
\hline Cultivar & & E quação & Valor de $r^{2}(\%)$ \\
\hline M açã & $\begin{array}{l}\mathrm{K}= \\
\mathrm{Ca}= \\
\mathrm{Mg}= \\
\mathrm{P}= \\
\mathrm{Fe}= \\
\mathrm{Mn}= \\
\mathrm{Zn}= \\
\mathrm{Cu}=\end{array}$ & $\begin{array}{c}57,178 \text { FMAs }-0,631 \\
23,943 \text { FMAs - 0,370 } \\
4,793 \text { FMAs - 0,052 } \\
3,097 \text { FMAs - 0,036 } \\
0,063 \text { FMAs }+83,931 \\
0,012 \text { FMAs }+18,074 \\
22,924 \text { FMAs }-0,103 \\
0,077 \text { F MAs }+4,113\end{array}$ & $\begin{array}{l}62,4^{* *(1)} \\
34,8^{\text {ns }} \\
50,4^{* *} \\
61,2^{* *} \\
0,4^{\text {ns }} \\
0,1^{\text {ns }} \\
46,9^{* *} \\
20,3^{\text {ns }}\end{array}$ \\
\hline Mysore & $\begin{array}{l}\mathrm{K}= \\
\mathrm{Ca}= \\
\mathrm{Mg}= \\
\mathrm{P}= \\
\mathrm{Fe}= \\
\mathrm{Mn}= \\
\mathrm{Zn}= \\
\mathrm{Cu}=\end{array}$ & $\begin{array}{c}0,068 \text { F MAs }-12,360 \\
-0,072 \text { F MAs }+6,637 \\
0,010 \text { F MAs }-1,195 \\
0,007 \text { F MAs }+0,501 \\
-0,560 \text { F MAs }+117,477 \\
1,006 \text { F MAs }-27,586 \\
-0,037 \text { F MAs }-19,042 \\
-0,024 \text { F MAs }+8,005\end{array}$ & $\begin{array}{l}10,1^{\text {ns }} \\
25,0^{\text {ns }} \\
21,0^{\text {ns }} \\
21,4^{\text {ns }} \\
22,6^{\text {ns }} \\
35,6^{\text {ns }} \\
12,4^{\text {ns }} \\
1,4^{\text {ns }}\end{array}$ \\
\hline Nanica & $\begin{array}{l}\mathrm{K}= \\
\mathrm{Ca}= \\
\mathrm{Mg}= \\
\mathrm{P}= \\
\mathrm{Fe}= \\
\mathrm{Mn}= \\
\mathrm{Zn}= \\
\mathrm{Cu}=\end{array}$ & $\begin{array}{c}0,313 \text { F MAs }+15,109 \\
0,006 \text { F MAs }+5,568 \\
0,023 \text { F MAs }+2,146 \\
0,019 \text { F MAs }+0,312 \\
-0,287 \text { F MAs }+107,149 \\
3,070 \text { F MAs }-60,631 \\
-0,106 \text { F MAs }+25,423 \\
-0,116 \text { F M As }+13,830\end{array}$ & $\begin{array}{c}44,5^{*} \\
0,5^{\text {ns }} \\
22,3^{\text {ns }} \\
49,3^{* *} \\
3,2^{\text {ns }} \\
7,5^{\text {ns }} \\
20,5^{\text {ns }} \\
8,4^{\text {ns }}\end{array}$ \\
\hline Pacovan & $\begin{array}{l}\mathrm{K}= \\
\mathrm{Ca}= \\
\mathrm{Mg}= \\
\mathrm{P}= \\
\mathrm{Fe}= \\
\mathrm{Mn}= \\
\mathrm{Zn}= \\
\mathrm{Cu}=\end{array}$ & $\begin{array}{c}0,018 \text { F MAs }+18,126 \\
-0,038 \text { F M As + 4,716 } \\
-0,011 \text { F M As }+3,250 \\
-0,028 \text { F MAs }+3,250 \\
1,241 \text { F MAs }-9,368 \\
-0,046 \text { F M As }+16,871 \\
-0,132 \text { F M As }+24,001 \\
-0,001 \text { F M As }+4,163\end{array}$ & $\begin{array}{r}0,1^{\text {ns }} \\
2,2^{\text {ns }} \\
1,2^{\text {ns }} \\
9,2^{\text {ns }} \\
11,1^{\text {ns }} \\
0,8^{\text {ns }} \\
9,5^{\text {ns }} \\
0,1^{\text {ns }}\end{array}$ \\
\hline Prata & $\begin{array}{l}\mathrm{K}= \\
\mathrm{Ca}= \\
\mathrm{Mg}= \\
\mathrm{P}= \\
\mathrm{Fe}= \\
\mathrm{Mn}= \\
\mathrm{Zn}= \\
\mathrm{Cu}=\end{array}$ & $\begin{array}{c}1,526 \text { F MAs - 24,544 } \\
0,258 \text { F MAs - 5,249 } \\
0,076 \text { F MAs }+0,397 \\
0,059 \text { F MAs - 0,667 } \\
0,066 \text { F MAs }+0,066 \\
-1,528 \text { F MAs }+100,221 \\
4,522 \text { F MAs }+0,384 \\
-0,083 \text { F MAs }+11,854\end{array}$ & $\begin{array}{c}25,3^{\text {ns }} \\
32,8^{\text {ns }} \\
7,6^{\text {ns }} \\
22,6^{\text {ns }} \\
0,1^{\text {ns }} \\
28,1^{\text {ns }} \\
41,1^{*} \\
3,2^{\text {ns }}\end{array}$ \\
\hline
\end{tabular}

(1) ns: não-significativo a $5 \%$; * ;* significativos a 5 e $1 \%$, respectivamente, pelo teste t. 
(Rodriguez-Goméz, 1980). Com base nessa referência, os níveis observados desses nutrientes (Quadro 2) não satisfazem às exigências nutricionais dos cultivares do presente estudo.

Os teores de micronutrientes obtidos nas fol has evidenciaram as seguintes seqüências: $\mathrm{Fe}$ : Maçã = Mysore $=$ Nanica $=$ Prata $>$ Pacovan; $M n$ : Maçã $=$ Nanica $=$ Prata $=$ Mysore $=$ Pacovan; Zn: Nanica $=$ Prata $>$ Maçã $=$ Mysore = Pacovan; Cu: Maçã = Mysore $=$ Nanica $=$ Prata $>$ Pacovan. Excetuando a Pacovan que apresentou a ordem $\mathrm{Fe}>\mathrm{Zn}>\mathrm{Mn}>\mathrm{Cu}$, todos os outros cultivares apresentaram, como seqüência decrescente, $\mathrm{Fe}>\mathrm{Mn}>\mathrm{Zn}>\mathrm{Cu}$.

Os teores de Fe foram sempre superiores aos de $\mathrm{Mn}, \mathrm{Zn}$ eCu, contrariando as afirmações de Gallo et al. (1972), Rodriguez-Goméz (1980) e Borges \& Cintra (1985), segundo os quais as bananeiras apresentam os teores de nutrientes na ordem $\mathrm{Mn}>\mathrm{Fe}>\mathrm{Zn}>\mathrm{Cu}$. A maior absorção de $\mathrm{Fe}$ pode ser devida ao el evado teor desse el emento no solo.

\section{Relações entre a colonização micorrízica e os teores de nutrientes nas folhas}

No quadro 3, encontram-se as equações de regressão que relacionam a colonização por fungos micorrízicos e nutrientes na parteaérea, envolvendo as épocas de coleta e os cultivares estudados. De acordo com o valor de $r^{2}$, sete de um total de 40 regressões foram significativas. Os cultivares Mysore e Pacovan não apresentaram relações significativas entre as características avaliadas. $\mathrm{Na}$ banana Maçã, as correlações significativas foram com os nutrientes $\mathrm{K}, \mathrm{Mg}, \mathrm{P}$ e Zn. Com relação a Nanica, os fungos micorrízicos contribuíram apenas para a absorção de K e P. Para a banana Prata a regressão foi significativa somente para o $\mathrm{Zn}$, indicando a importância da associaçãofungox planta para a absorção de outros el ementos, princi pal mente os de baixa mobilidade no solo (Silveira, 1992, Colozzi-Filho \& Balota, 1994). Essa constatação confirma os estudos desenvolvidos por Oliveira et al. (1999), que registraram correlações lineares positivas entre micorrizas e o $\mathrm{P}$ na J acareúba (Calophyllum angulare) e o Zn no Marupá (Simaruba amara), em um Podzólico da Amazônia. A micorrização exerce efeito acentuado na concentração de outros nutrientes além do $P$ (Colozzi-Filho \& Siqueira, 1986). Efeitos positivos foram observados em rel ação ao Ca, Mg, K, P, S, Zn e Cu (Silveira, 1992; Marschner \& Dell, 1994; Oliveira et al., 1999; Oliveira \& Oliveira, 2000).

A absorção dos demais macro e micronutrientes não se relacionou com os fungos micorrízicos, embora outros estudos tenham evidenciado alguma influência (Chu \& Kato, 1992; Colozzi-Filho \& Balota, 1994; Oliveira et al., 1999). Correlações significativas entre os nutrientes nas fol has e as percentagens de colonização por fungos mi corrízicos nas raízes são indicativos de alguma contribuição das micorrizas na absorção desses nutrientes. No entanto, a ausência dessas correlações não significa falta de contribuição, pois o aspecto "eficiência" não foi considerado. Fungos micorrízicos podem apresentar col onizações semel hantes nas raízes, mas podem favorecer diferentemente a absorção de nutrientes, conforme observado por Bonetti (1984) em siratro, com relação ao P.

\section{CONCLUSÕES}

1. Os cultivares de bananeiras apresentaram diferentes níveis de col onização radicular por fungos micorrízicos arbusculares nos quatro meses de amostragem.

2. As bananeiras apresentaram teores foliares de macro ( $\mathrm{Ca}, \mathrm{Mg}$ e P) e micronutrientes ( $\mathrm{Fe}, \mathrm{Mn}, \mathrm{Zn}$ e $\mathrm{Cu}$ ) inferiores às exigências nutricionais dos cultivares.

3. A associação micorrízica correlacionou-se com os teores de $\mathrm{K}, \mathrm{Mg}, \mathrm{P}$ e Zn no cultivar Maçã, $\mathrm{K}$ e $\mathrm{P}$ na Nanica e Zn na banana Prata.

\section{LITE RATURA CITADA}

ABBOTT, L.K. \& ROBSON, A.D. Factors influencing the occurrence of vesicular-arbuscular mycorrhizas. Agric. Ecosyst. Environ., 35:121-150, 1991.

ALVES, E.J . A cultura da banana no Brasil e proposições para o seu melhoramento. 2.ed. Cruz das Almas, Empresa Brasileira de Pesquisa Agropecuária, 1991. 40p.

BONETTI, R. Efeito de micorrizas vesiculares arbusculares na nodulação, crescimento e absorção de fósforo e nitrogênio em siratro. R. Bras. Ci. Solo, 8:189-192, 1984.

BORGES, A.L. \& CINTRA, F.L.D. Estudo de níveis de potássio em bananeiras do grupo "Prata" e "Terra". In: EMPRESA BRASILEIRA DE PESQUISA AGROPECUÁRIA. Centro Nacional de Pesquisa de Mandioca e Fruticultura, Cruz das Almas, BA. Cruz das Almas, 1985. p.94-98. (Relatório Técnico Anual 1984)

BRUNDRETT, M. Mycorrhizas in natural ecosystems. Adv. Ecol. Res., 21:171-313, 1991.

COLOZZI-FILHO, A. \& SIQUEIRA, J.O. Micorrizas vesículoarbusculares em mudas de cafeeiro. I. Efeito da inoculação e adubação fosfatada no crescimento e nutrição. R. Bras. Ci. Solo, 10:199-205, 1986. 
COLOZZI-FILHO, A. \& BALOTA, E.L. Micorrizas arbusculares. In: HUNGRIA, M. \& ARAÚJ O, R.S., eds. Manual de métodos empregados em estudos em microbiologia agrícola. Brasília, Empresa Brasileira de Pesquisa Agropecuária, 1994. p.383-418.

CHU, E,Y. \& KATO, O.R. Efeito da inoculação de fungos micorrízicos vesicular-arbusculares em urucuzeiro (Bixa orellana L.). Belém, Empresa Brasileira de Pesquisa Agropecuária, 1992. 15p. (Boletim de Pesquisa, 128)

DECLERCK, S.; PlenChetTe, C. \& STRuLLU, D.G. Mycorrhizal dependency of banana (Musa acuminata, AAA group) cultivar. Plant Soil, 176:183-187, 1995.

EMPRESA BRASILEIRA DE PESQUISA AGROPECUÁRIA - EMBRAPA. Serviço Nacional de Levantamento e Conservação do Solo. Manual de métodos de análise de solos. 2.ed. Rio de J aneiro, 1997. 212p.

EMPRESA BRASILEIRA DE PESQUISA AGROPECUÁRIA - EMBRAPA. Análise foliar. Laboratório de análise de solos e plantas. Belém, Embrapa/Centro de Pesquisa de Seringueira e Dendê, 1988. 8p.

GALLO, J.R.; BATAGLIA, O.C.; FURLANI, P.R.; HIROCE, R.; FURLANI, A.M.C.; RAMOS, M.T.B. \& MOREIRA, R.S. Composição química e inorgânica da bananeira (Musa acuminata Simmonds. cultivar Nanicão). Ci. Cult., 24:70-79, 1972.

GIOVANETTI, M. \& MOSSE, B. An evaluation of techniques for measuring vesicular arbuscular mycorrhizal infection in roots. New Phytol., 84:489-500, 1980.

GOMEZ, K.A. \& GOMEZ, A.A. Statistical procedures for agricultural research. New York, J ohn Wiley \& Sons, 1984. 680p.

IYER, R.; MOOSA, H. \& KALPANA SASTRY, R. Vesiculararbuscular mycorrhizal association in banana. Current Sci., 57:153-155, 1988.

J AIZME-VEJ A, M.C. \& AZCÓN, R. Responses of some tropical and subtropical cultures to endomycorrhizal fungi. Micorrhiza, 5:213-217, 1995.

KORMANICK, P.P.; BRYAN, W.C. \& SCHULTZ, R.C. Procedures and equipament for staining large numbers of plant root samples for endomycorrhizal assay. Can. J. Microbiol., 26:536-538, 1980.

MALAVOLTA, E. Manual de química agrícola, adubos e adubação. 3.ed. São Paulo, Ceres, 1981. 528p.

MARSCHNER, H. \& DELL, B. Nutrient uptake in mycorrhizal symbiosis. Plant Soil, 159:89-102, 1994.

MEDINA, J.C. Cultura da banana. In: MEDINA, J.C.; BLEINROTH, E.W.; DE MARTIN, Z.J .; TRAVAGLINI, D.A.; OKADA, M.; QUAST, D.G.; HASHIZUNE, T.; MORETTI, V.A.; NETO, L.C.B.; ALMEIDA, L.A.S.B. \& RENESTO, O.V., eds. Banana. 2.ed. Campinas, 1995. p.1-132.
MELO, A.M.Y.; MAIA, L.C. \& MORGADO, L.B. Fungos micorrízicos arbusculares em bananeiras cultivadas no Vale do Submédio São Francisco. Acta Bot. Bras., 11:115-121, 1997.

OLIVEIRA, A.N. \& OLIVEIRA, L.A. Influência da colonização por fungos micorrízicos arbusculares (FMAS) na absorção de nutrientes pelo cupuaçu e guaraná em um Sistema Agroflorestal da Amazônia. In: CONGRESSO BRASILEIRO DE SISTEMAS AGROFLORESTAIS, 3., Manaus, 2000. Resumos. Manaus, Embrapa Amazônia Ocidental, 2000. p.204206.

OLIVEIRA, L.A.; MOREIRA, F.M.S. \& MOREIRA, F.W. Ocorrências de microrganismos benéficos e ecossistemas amazônicos. In: NODA, H.; SOUZA, L.A.G. \& FONSECA, O.J .M., eds. Duas décadas de contribuições do INPA à pesquisa agronômica no trópico úmido. Manaus, 1997. p.221-240.

OLIVEIRA, A.N.; OLIVEIRA, L.A. \& RAMOS, M.B.P. Ocorrências de micorrizas arbusculares (MAs) em cinco cultivares de bananeira (Musa spp.) num cultivo experimental em Latossolo Amarelo da Amazônia Ocidental. In: MOSTRA TÉCNICO CIENTÍFICA DA UNIVERSIDADE FEDERAL DO AMAZONAS, Manaus, 1999a. Resumos. Manaus, 1999a, Universidade F ederal do Amazonas, 1999. p11.

OLIVEIRA, L.A.; GUITTON, T.L. \& MOREIRA, F.W. Relações entre as colonizações por fungos micorrízicos arbusculares e teores de nutrientes foliares em oito espécies florestais da Amazônia. Acta Amazonica, 29:183-193, 1999b.

RANZANI, G. I dentificação e caracterização de al guns solos da Estação Experimental de Silvicultura Tropical do INPA. Acta Amazonica, 10:7-41, 1980.

RIBEIRO, M.N.G. Aspectos climáticos de Manaus. Acta Amaz., 6:229-233, 1976.

RODRIGUEZ-GOMÉZ, M. Estudios preliminares sobre la nutrición com potasio de los bananales en America Central. Fruits, 35:283-291, 1980.

SAGGIN-J ÚNIOR, O.J .; SIQUEIRA, J .O.; GUIMARÃES, P.T.G. \& OLIVEIRA, E. Interação fungos micorrízicos versus superfosfato e seus efeitos no crescimento e teores de nutrientes do cafeeiro em solo não fumigado. R. Bras. Ci. Solo, 18:27-36, 1994.

SILVA, O. Fertilizantes, corretivos e solos: O tripé das plantas. Campinas, Instituto Campinense de Ensino Agrícola, 1997. 55p.

SILVEIRA, A.P.D. Micorrizas. In: CARDOSO, E.J.B.N.; TSAI, S.M. \& NEVES, M.C.P., eds. Microbiologia do solo. Campinas, Sociedade Brasileira de Ciência do Solo, 1992. p.257-282.

SIQUEIRA, J.O. \& SAGGIN-J ÚNIOR, O.J. The Importance of mycorrhizae in natural low-fertility soils. In: MACHADO, A.T.; MAGNAVACA, R.; PANDEY, S. \& SILVA, A.F. INTERNATIONAL ENVIRONMENTAL STRESS, MAIZE IN PERSPECTIVE, México, 1995. Proceedings. México, Embrapa, 1995. p.240-280. 
SIQUEIRA, J .O. Micorrizas arbusculares. In: ARAÚJ O, R.S. \& HUNGRIA, M., eds. Microrganismos de importância agrícola. Brasília, Empresa Brasileira de Pesquisa Agropecuária, 1994. p.151-194.
ST. J OHN, T.V. \& UHL, C. Mycorrhizae in the rain forest at San Carlos de Rio Negro, Venezuela. Acta Ci. Venez., 34:233-237, 1983. 